\title{
COST-EFFECTIVENESS ANALYSIS AFTER THE IMPLEMENTATION OF AN ERAS PROTOCOL IN ELECTIVE COLORECTAL SURGERY
}

Cabellos Olivares, M; Muñoz Expósito, R; Labalde Martínez, M; Torralba González, M; Rodríguez Fraile, JR; Atance Martínez, JC.

\section{INTRODUCTION}

ERAS (Enhanced Recovery After Surgery) protocols in colorectal surgery reduce hospital stay and complications, but there are few studies on whether they are cost-effective.
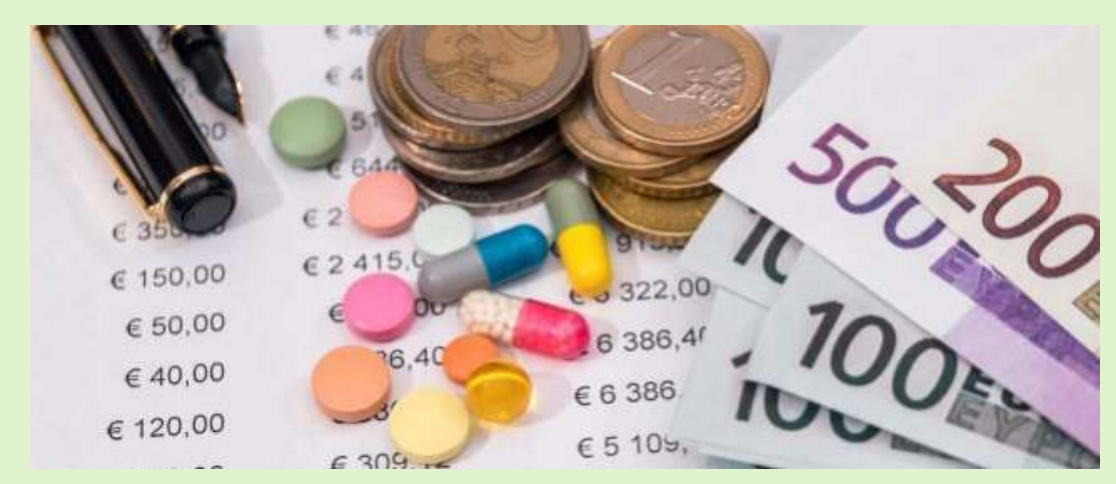

\section{METHODS}

We compared a group of 121 patients (ERAS group) consecutively operated on elective colorectal surgery according to an ERAS protocol, with a historical cohort of 135 patients (preERAS group) operated prior to the implantation of the protocol.

- Inclusion criteria: elective colorectal surgery, $\geq 18$ years old, appropriate cognitive state and ASA I-II-III.

- Exclusion criteria: urgent surgery, and existence of higher concomitant surgical processes.

- A univariate analysis was performed to compare the data of stay, complications, readmissions and cost effectiveness.
RESULTS

\begin{tabular}{|c|c|c|c|}
\hline \multicolumn{4}{|c|}{$\begin{array}{l}\text { TABLE 1. DEMOGRAPHIC AND CLINICAL } \\
\text { CHARACTERISTICS IN BOTH GROUPS }\end{array}$} \\
\hline & preERAS $(\mathrm{n}=135)$ & ERAS $(n=121)$ & $\mathrm{p}$ \\
\hline Age & $68,4 \pm 12,3$ & $68,4 \pm 13,4$ & 0,169 \\
\hline Male sex & $94(69,6 \%)$ & $77(63,6 \%)$ & 0,309 \\
\hline $\begin{array}{l}\text { ASA } 1 \\
\text { ASA } 2 \\
\text { ASA } 3\end{array}$ & $\begin{array}{c}10(7,4 \%) \\
86(64,7 \%) \\
39(28,9 \%)\end{array}$ & $\begin{array}{c}12(9,9 \%) \\
66(54,6 \%) \\
43(35,5 \%)\end{array}$ & 0,325 \\
\hline $\begin{array}{l}\text { Surgical approach: } \\
\text {-Laparoscopy * } \\
\text {-Open surgery } \\
\text {-Reconversion }\end{array}$ & $\begin{array}{c}27(20 \%) \\
105(77,8 \%) \\
3(2,2 \%) \\
\end{array}$ & $\begin{array}{c}45(37,2 \%) \\
74(61,2 \%) \\
2(1,7 \%) \\
\end{array}$ & 0,006 \\
\hline $\begin{array}{l}\text { Complications } \\
\text { rate }\end{array}$ & $49(36,3 \%)$ & $38(31,4 \%)$ & 0,49 \\
\hline $\begin{array}{l}\text { Clavien-Dindo } \\
\text { complications: } \\
\text { - Grade } 1 \\
\text { - Grade } 2 \\
\text { - Grade } 3 \\
\text { - Grade } 4 \\
\text { - Grade } 5\end{array}$ & $\begin{array}{c}21(15,5 \%) \\
13(9,6 \%) \\
14(10,4 \%) \\
0(0 \%) \\
1(0,7 \%)\end{array}$ & $\begin{array}{c}8(6,6 \%) \\
17(14 \%) \\
11(9,1 \%) \\
0(0 \%) \\
2(1,7 \%)\end{array}$ & 0,174 \\
\hline ICU & 0 & $2(1,7 \%)$ & 0,134 \\
\hline $\begin{array}{l}\text { Mortality at } 30 \\
\text { days }\end{array}$ & $1(0,7 \%)$ & $2(1,7 \%)$ & 0,498 \\
\hline $\begin{array}{l}\text { Length of stay } \\
\text { (days) * }\end{array}$ & $11 \pm 3,8$ & $9,8 \pm 3,7$ & 0,018 \\
\hline $\begin{array}{l}\text { Readmission at } \\
30 \text { days }\end{array}$ & $15(11,1 \%)$ & $12(9,9 \%)$ & 0,756 \\
\hline
\end{tabular}

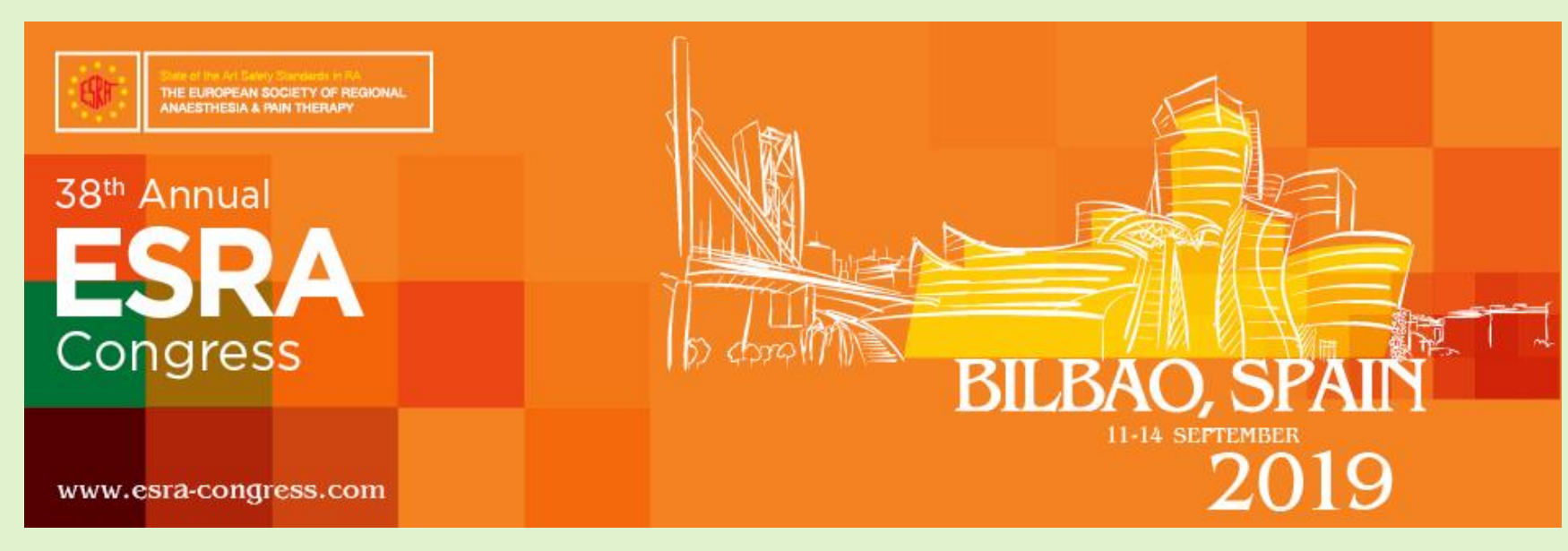

\begin{tabular}{|c|c|c|c|}
\hline \multicolumn{4}{|c|}{ TABLE 2. HEALTHCARE COSTS } \\
\hline & $\begin{array}{c}\text { preERAS } \\
(\mathrm{n}=\mathbf{1 3 5})\end{array}$ & $\begin{array}{c}\text { ERAS } \\
(n=121)\end{array}$ & $p$ \\
\hline $\begin{array}{l}\text { Total } \\
\text { expenditure } \\
\text { per patient } \\
(€)\end{array}$ & $\begin{array}{r}1618,8 \\
\pm 830,5\end{array}$ & $\begin{array}{r}1578,6 \\
\pm 491,1\end{array}$ & 0,634 \\
\hline Median & 1324 & 1503,05 & \\
\hline Minimum & 778,2 & 638,96 & \\
\hline Maximum & 7782,2 & 3058 & \\
\hline $\begin{array}{l}\text { 25th } \\
\text { percentile }\end{array}$ & 1149,6 & 1184,1 & \\
\hline $\begin{array}{l}\text { 75th } \\
\text { percentile }\end{array}$ & 1885 & 1871,1 & \\
\hline
\end{tabular}

Laparoscopic surgery independently
reduced the hospital stay and the rate of
readmissions, while the presence of severe
complications increased them.

\section{CONCLUSIONS}

The application of an ERAS protocol in elective colorectal surgery is costeffective, since it improves the results obtained without increasing healthcare costs. 